\title{
Histological modification in TRAM flap in rats treated with pentoxifylline ${ }^{1}$
}

\author{
Audrien Furlan de LuccaI, Adriano Guimarães Brasolin', Roney Gonçalves Fechine Feitosa'II, Milvia Maria Simões e Silva \\ Enokihara $^{\text {III, Heitor Francisco de Carvalho Gomes }}{ }^{\mathrm{IV}}$, Lydia Masako Ferreira ${ }^{\mathrm{V}}$
}

DOI: http://dx.doi.org/10.1590/S0102-86502014001400007

IMD, Plastic Surgeon, Plastic Surgery Division, Surgery Department, UNIFESP;

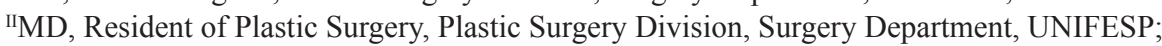

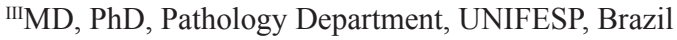

${ }^{\mathrm{IV}} \mathrm{PhD}$, Associate Professor, Plastic Surgery Division, Surgery Department, UNIFESP, Brazil

${ }^{v}$ Head and Full Professor, Plastic Surgery Division, UNIFESP, Researcher 1A-CNPq, Director Medicine III-CAPES, Sao Paulo-SP, Brazil.

\section{ABSTRACT}

PURPOSE: To investigate the blood vessels' concentration in TRAM flap's rat model, in the presence of pentoxifylline.

METHODS: 32 male, Wistar-EPM rats were divided into two groups. Control group (C): $0.5 \mathrm{ml}$ of saline, intraperitoneally, once a day, for seven days before flap elevation; PTX group (P): pentoxifylline (20mg/kg/day), intraperitoneally, for seven days before flap elevation. After that, they were submitted to a caudal unipedicle TRAM flap. On the fifth postoperative day, percentages of flap necrosis were determined via the "paper template" method and Tram flap's zone IV skin biopsies were taken for histological analysis.

RESULTS: the mean percentage of flap necrosis in group C was $58.7 \%$ and in group P, 31.1 (Wilcoxon test; $p=0.003$ ). Mean capillary vessels number in zone IV's skin in C group was 33.4 and in P group was 71.9 ( $p=0.008)$.

CONCLUSIONS: Pentoxifylline was effective reducing the necrosis in the caudal unipedicle TRAM flap in the rat as well as increasing the number of capillaries in an ischemic zone (zone IV).

Key words: Pentoxifylline. Surgical flaps. Graft survival. Rats. 


\section{Introduction}

The Transverse Rectus Abdominis Myocutaneous flap (TRAM flap) became one of the main techniques for breast reconstruction after mastectomy. Despite great advances in reconstructive surgery in the last decades, a number of difficulties and complications remain. Among them, the most worrying is necrosis ${ }^{1-3}$.

Both extrinsic and intrinsic factors are involved in the genesis of TRAM flap's necrosis, but the main villain is insufficient blood flow, an intrinsic aspect ${ }^{1,3,4}$. Necrosis in the TRAM flap, for the most part in zone IV, the most distant from the pedicle, has been of great concern ${ }^{5-7}$.

Numerous researches were performed in order to find a way to increase TRAM flap's viability. TRAM flap's rat model simulates the procedure and allows studies on flap perfusion and viability. Drug induced TRAM flap's necrosis reduction was obtained, mainly by stimulating its microcirculation, but surgeons still look for a more efficient drug ${ }^{2,5,6}$.

Pentoxifylline, a sub product of methylxantine, improves tissue perfusion in peripheral vascular disease. It acts in the microcirculation, augmenting erythrocytes' flexibility and reducing blood viscosity, by lowering plasmatic fibrinogen levels. It has a thromboprophylatic effect, as well as an influence in the reduction of neutrophylic infiltration and in the inhibition of production of $\alpha$-TNF by inflammatory cells ${ }^{6-12}$. Experimental studies showed that pentoxifylline significantly reduced skin flaps' necrosis in rats, when used before the surgical procedure, but the exact mechanisms involved remain unclear.

This study aimed at investigating blood vessels' concentration in TRAM flap's rat model, in the presence of pentoxifylline.

\section{Methods}

Thirty two Wistar-EPM rats were selected, at random, weighted (mean $300 \mathrm{~g}$ ), kept in individual cages and kept without any alimentary restriction until study's day, when they were randomly separated in two groups:

C Group ( $\mathrm{n}=16)$ - control: caudally based unipedicle TRAM flap and saline $(0.5 \mathrm{ml})$, intraperitoneally, once a day, for seven days before flap elevation;

$P$ Group $(n=16)$ - pentoxifylline: same flap and pentoxifylline $(20 \mathrm{mg} / \mathrm{kg}$ in $0.5 \mathrm{ml})$, intraperitoneally, once a day, for seven days before flap elevation.

After this preoperative period, the rats were anesthetized with Tiletamin Chloridrate $(25 \mathrm{mg} / \mathrm{kg})$ and Zolazepam Chloridrate
(25 $\mathrm{mg} / \mathrm{kg}$ ), intraperitoneally and positioned in dorsal decubit on a flat surface, immobilized with extended limbs and manually depilated in the abdominal areas. The TRAM flap $(3 \times 5 \mathrm{~cm})$ was then delineated and elevated.

On the fifth postoperative day, the rats were anesthetized and the percentages of flaps' necrosis determined via the "paper template method"13. The limit between viable (soft skin, rosy, warm and with hair) and necrotic tissue (stiff skin, dark, cool and without hair) was demarcated in the animals and the percentage of necrosis calculated.

Tram flap's zone IV biopsies were taken in the $5^{\text {th }}$ postoperative day. Skin fragments were fixed in 10\% bufferedformalin and embedded in paraffin for serial sectioning. Longitudinal $5-\mu \mathrm{m}$ sections were stained with hematoxilin and eosin (HE) and Masson's trichrome. Morphologic analysis was performed in HE stained sections, while capillaries quantification was done in Masson's trichrome stained areas. Morphometry was completed with a grade connected to an optic microscope's ocular with a 10x objective (100x final augmentation). Five sites were selected, at random, for number of capillaries count. The final result was the average of capillary vessels in these sites.

\section{Statistical analysis}

Considering the nature of the data involved in this study (percentages of necrosis), non parametric tests were used. Wilcoxon sum of ranks test (non parametric, independent groups) was used to compare $\mathrm{C}$ and $\mathrm{P}$ groups, as regards flaps' percentages of necrosis. Student's $t$ test for independent samples was used to analyze capillary vessels number. The significance level was fixed in 0.05 or $5 \%(\mathrm{p} \leq 0.05)$.

\section{Results}

Mean flap's percentage of necrosis in C group (control) was $58.7 \%$ and in P group (pentoxifylline), 31.1\%. Wilcoxon's test for independent groups showed a significant difference $(p=0.002)$ (Figure 1). Mean capillary vessels number in zone IV's skin in C group was 33.4 and in $\mathrm{P}$ group was 71.9 , a significant difference $(\mathrm{p}=0.008)$ (Figure 2). 


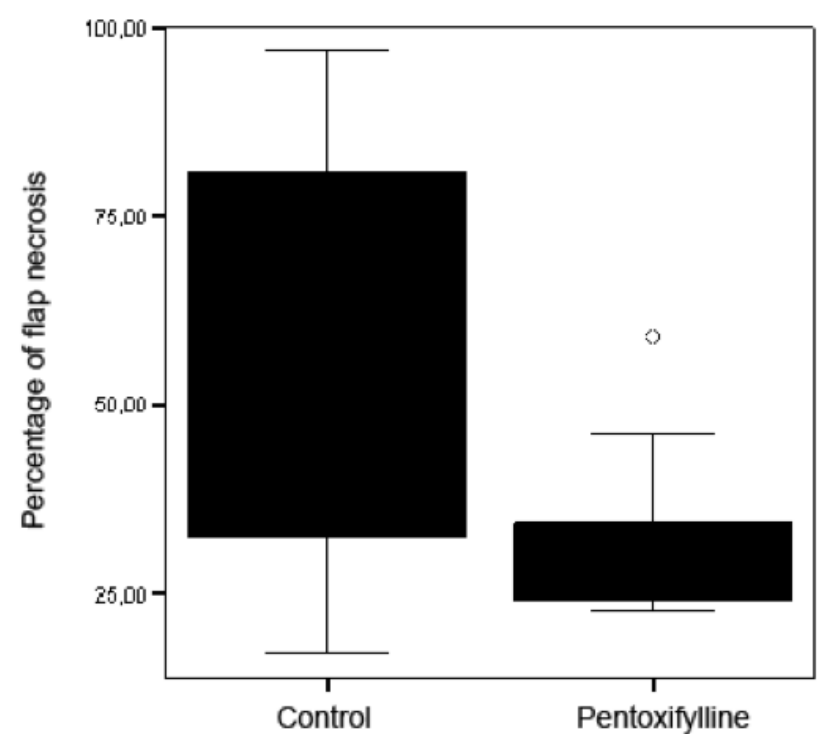

FIGURE 1 - Mean percentages of TRAM flap's necrosis in control and pentoxifylline groups.

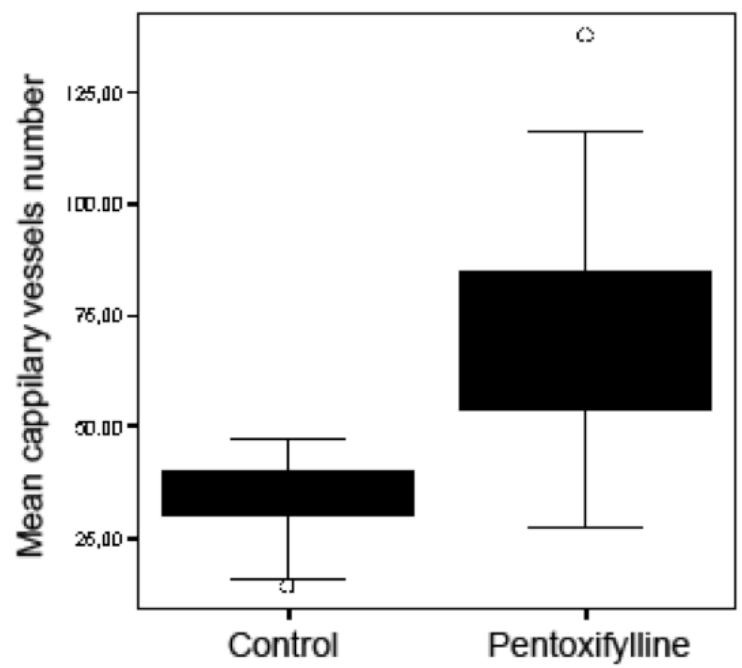

FIGURE 2 - Mean capillary vessels number in zone IV's skin, per site.

\section{Discussion}

The incidence of breast cancer in caucasian women is growing. Treatment involves radical mastectomy in a significant percentage of patients, leading to the use of a number of mammary reconstruction techniques. The transverse rectus abdominis myocutaneous flap (TRAM) is frequently used, but necrosis in distant from the pedicle areas is of great concern ${ }^{5,14}$. Pharmacological therapy represents an alternative strategy to avoid this complication.

The present study used an experimental model of TRAM flap, in the rat. This is a practical, inexpensive and effective method to study drugs' effects and their influences on flap's perfusion and viability $^{5}$.
Despite great differences, humans and rats share similarities in the vascular anatomy of the rectus abdominis muscle. Notwithstanding, the human's superior vascular pedicle is equivalent to the rat's caudal pedicle ${ }^{5,15,16}$.

Clugston et al. ${ }^{6}$ designed a study with the flap raised in the cranial pedicle (dominant pedicle in rats), showing, as expected, greater flap viability with pentoxifylline.

In the herein presented work, the caudal pedicle was elected, thus allowing better comparison with the daily clinical practice in humans (with superior pedicle), as previously remembered by Hallock et at. ${ }^{5}$.

Previous studies showed pentoxifylline's favorable effects in a number of surgical procedures $2,6,7,8,11,12,17$. Pentoxifylline, a haemorreologic agent, presents properties that protect tissues from ischemic damages. This drug increases erythrocytes' deformability by raising ATP and cyclic-AMP levels. These elements participate in proteins phosphorilation inside erythrocyte's membrane, reduction in plasmatic concentration of fibrinogen and reduction in endothelial adherence of granulocytes, reducing blood viscosity ${ }^{9,10,18}$. In spite of this haemorreologic effects and thanks to its' capacity to inhibit platelet aggregation (due to increase in the availability of ATP, pentoxifylline does not alter normal blood coagulation $)^{17}$.

Shimizu et $a l .{ }^{13}$ showed that intraperitoneal administration of pentoxifylline, for 7 days in the preoperative period and in both preoperative ( 7 days) and postoperative (7 days) periods, were both efficient in improving viability in ischemic tissues. An explanation for the efficiency of the preoperative administration could be the 40 days erythrocytes half-life in young rats $^{19}$. Pentoxifylline does not have acute effects in erythrocytes' membranes, thus it is not effective when administered in the postoperative period alone ${ }^{13,20}$.

The present work showed that pentoxifylline reduced necrosis in the caudal unipedicle TRAM flap in the rat, in

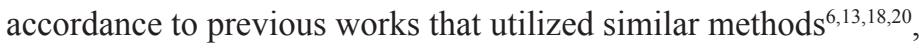
an evidence of the positive effect of this drug in reducing deleterious consequences of ischemia (Wilcoxon test, $\mathrm{p}=0.003$ ). However, the exact changes that pentoxifylline promoted have not been herein assessed. It was demonstrated that this drug led to an increase in the number of capillaries in an ischemic zone (zone IV), which could be a positive factor to explain the boost in the flap's viability area in pentoxifylline treated animals.

The present work did not elucidate the precise mechanisms by which pentoxifylline determined changes at the flap's microcirculation system, but it demonstrated that modification of an intrinsic factor (increase in blood circulation) led to improvement 
in TRAM flap's viability. Recognition that the increase in this viability area is mainly due to an increase in capillaries, illustrates the powerful effect of blood flow in ischemic areas of this flap.

\section{Conclusions}

Pentoxifylline had a beneficial effect in TRAM flap's survival, in the rat. The results herein presented support the clinical use of pentoxifylline in mammary reconstruction with the TRAM flap.

\section{References}

1. Alderman AK, Wilkins EG, Kim HM, Lowery JC. Complications in postmastectomy breast reconstruction: two-year results of the Michigan Breast Reconstruction Outcome Study. Plast Reconstr Surg. 2002;109:2265-74.

2. Lai YL, Yu YL, Centeno RF, Weng CJ. Breast augmentation with bilateral deepithelialized TRAM flaps: an alternative approach to breast augmentation with autologous tissue. Plast Reconstr Surg. 2003;112:302-8

3. Erdmann D, Sundin BM, Moquin KJ, Young H, Georgiade GS. Delay in unipedicled TRAM flap reconstruction of the breast: a review of 76 consecutive cases. Plast Reconstr Surg. 2002;110:762-7.

4. Campos H, Ferreira LM, Santos WLC, Araújo MCM. Efeitos da nicotina nos retalhos cutâneos em ratos. Acta Cir Bras. 2001;16(4):206-10.

5. Ely PB, Ferreira LM. Transverse rectus abdominis musculocutaneous flap (TRAM flap) em ratos. Acta Cir Bras. 2003;18(n. spe):46-53.

6. Clugston PA, Perry LC, Fisher J, Maxwell GP. A rat transverse rectus abdominis musculocutaneous flap model: effects of pharmacological manipulation. Ann Plast Surg. 1995;34:154-61.

7. Karacaoglan N, Akbas H. Effect of parenteral pentoxifylline and topical nitroglycerin on skin flap survival. Otolaryngol Head Neck Surg. 1999;120:272-4.

8. Murthy P, Riesberg MV, Hart S, Bustillo A, Duque CS, Said S, Civantos FJ. Efficacy of perioperative thromboprophylactic agents in the maintenance of anastamotic patency and survival of rat microvascular free groin flaps. Otolaryngol Head Neck Surg. 2003;129:176-82.

9. Bayat M, Chelcheraghi F, Piryaei A, Rakhshan M, Mohseniefar Z, Rezaie F, Bayat M, Shemshadi H, Sadeghi Y. The effect of 30-day pretreatment with pentoxifylline on the survival of a random skin flap in the rat: an ultrastructural and biomechanical evaluation. Med Sci Monit. 2006;12:201-7.
10. Reid HL, Dormandy JA, Barnes AJ. Impaired red cell deformability in peripheral vascular disease. Lance. 1976;2:666-8.

11. Muller R, Lehrach F. Haemorheological role of platelet aggregation and hypercoagulability in microcirculation: therapeutical approach with pentoxifylline. Pharmatherapeutica. 1980;2:372-9.

12. Kronen G, Ferder M, Hunzicker K, Strauch B. The use of pentoxifylline in microvascular surgery. J Reconstr Microsurg. 1994;10:17-20.

13. Shimizu N, Watanabe T, Arakawa T, Fujiwara Y, Higuchi K, Kuroki T. Pentoxifylline accelerates gastric ulcer healing in rats: roles of tumor necrosis factor alpha and neutrophils during the early phase of ulcer healing. Digestion. 2000;61:157-64.

14. Sasaki GH, Pang CY. Hemodynamics and viability of acute neurovascular island skin flap in rats. Plast Reconstr Surg. 1980;65:152-8.

15. Wong MS, Erdmann D, Sweis R, Pöllmann C, Farrar M, Georgiade GS, Levin LS, Olbrich KC, Klitzman B. Basic fibroblast growth factor expression following surgical delay of rat transverse rectus abdominis myocutaneous flaps. Plast Reconstr Surg. 2004;113:2030-6.

16. Hallock GG, Rice DC. Cranial epigastric perforator flap: a rat model of true perforator flap. Ann Plast Surg. 2003;50:393-7.

17. Hallock GG, Rice DC. Physiologic superiority of the anatomic dominant pedicle of the TRAM flap in rat. Plast Reconstr Surg. 1995;96:111-8.

18. Aker JS, Mancoll J, Lewis B, Colen LB. The effect of pentoxifylline on random-pattern skin-flap necrosis induced by nicotine treatment in the rat. Plast Reconstr Surg. 1997;100:66-71.

19. Han S, Sup Eom J, Ho Kim D. Effects of the abdominal midline incision on the survival of the transverse rectus abdominis musculocutaneous flap in rat model. Ann Plast Surg. 2003;50:171-6.

20. Mauad RJ Jr, Shimizu MH, Mauad T, de Tolosa EM. Buflomedil and pentoxifylline in the viability of dorsal cutaneous flaps of rats treated with nicotine. J Plast Reconstr Aesthet Surg. 2006;59:387-92.

\section{Correspondence:}

Audrien Furlan de Lucca

Roney Gonçalves Fechine Feitosa

Rua Napoleão de Barros, $715 / 4^{\circ}$ andar

04024-900 São Paulo - SP Brasil

Tel.: (55 11)5576-4118

Fax: (55 11)5571-6579

aflucca@yahoo.com.br

roneyfechine@gmail.com

${ }^{1}$ Research performed at Plastic Surgery Division, Surgery Department, Federal University of Sao Paulo (UNIFESP), Brazil. 